\title{
Cytocompatible antifungal acrylic resin containing silver nanoparticles for dentures
}

\author{
This article was published in the following Dove Press journal: \\ International Journal of Nanomedicine \\ 3I August 2012 \\ Number of times this article has been viewed
}

\author{
Laura Susana Acosta- \\ Torres' \\ Irasema Mendieta ${ }^{2}$ \\ Rosa Elvira Nuñez-Anita ${ }^{3}$ \\ Marcos Cajero-Juárez ${ }^{3}$ \\ Víctor M Castaño ${ }^{4}$ \\ 'National School of Higher Education, \\ School of Dentistry - Leon Unit, \\ National Autonomus University of \\ Mexico (UNAM), Leon, Guanajuato, \\ ${ }^{2}$ Neurobiology Institute, National \\ Autonomus University of Mexico \\ (UNAM), Juriquilla, Queretaro, \\ ${ }^{3}$ Animal Biotechnology Laboratory, \\ Faculty of Veterinary Medicine at \\ San Nicolas de Hidalgo, Michoacán \\ University, Michoacán, ${ }^{4}$ Molecular \\ Materials Department, Applied Physics \\ and Advanced Technology Center, \\ National Autonomus University of \\ Mexico (UNAM), Juriquilla, Queretaro, \\ Mexico
}

Background: Inhibition of Candida albicans on denture resins could play a significant role in preventing the development of denture stomatitis. The safety of a new dental material with antifungal properties was analyzed in this work.

Methods: Poly(methyl methacrylate) [PMMA] discs and PMMA-silver nanoparticle discs were formulated, with the commercial acrylic resin, Nature-Cryl ${ }^{\mathrm{TM}}$, used as a control. Silver nanoparticles were synthesized and characterized by ultraviolet-visible spectroscopy, dispersive Raman spectroscopy, and transmission electron microscopy. The antifungal effect was assessed using a luminescent microbial cell viability assay. Biocompatibility tests were carried out using NIH-3T3 mouse embryonic fibroblasts and a Jurkat human lymphocyte cell line. Cells were cultured for 24 or 72 hours in the presence or absence of the polymer formulations and analyzed using three different tests, ie, cellular viability by 3-(4,5-dimethylthiazol-2-yl)2,5-diphenyltetrazolium bromide (MTT) assay, and cell proliferation by enzyme-linked immunosorbent assay BrdU, and genomic DNA damage (Comet assay). Finally, the samples were evaluated mechanically, and the polymer-bearing silver nanoparticles were analyzed microscopically to evaluate dispersion of the nanoparticles.

Results: The results show that PMMA-silver nanoparticle discs significantly reduce adherence of $C$. albicans and do not affect metabolism or proliferation. They also appear not to cause genotoxic damage to cells.

Conclusion: The present work has developed a new biocompatible antifungal PMMA denture base material.

Keywords: cytotoxicity, genotoxicity, dental polymers, denture bases, Candida albicans, antifungal effect

\section{Introduction}

The main purposes of dentures are to restore dental function, facial appearance, and maintain the wearer's health. ${ }^{1}$ Adherence of Candida albicans to host cells or polymers, such as denture acrylic resin, is an essential and necessary first step in successful colonization and development of infection. ${ }^{2}$ Development of denture stomatitis is influenced by, among other factors, the denture base material. ${ }^{3} \mathrm{~A}$ prosthesis placed in the oral cavity leads to changes in environmental conditions, preventing the mechanical cleansing effect of the tongue and salivary flow, and encouraging formation and deposit of biofilms on both prosthetics and adjacent mucosa. ${ }^{4}$

Dentures are made of poly(methyl methacrylate) (PMMA) acrylic resin. ${ }^{5}$ The inner surface of the prosthesis is rough, ${ }^{6}$ and in addition to local (eg, poor hygiene, local trauma, tissue integrity loss) and systemic factors (eg, malnutrition, diabetes mellitus,
Correspondence: Víctor M Castaño Blvd Juriquilla 3000 , Juriquilla,

Querétaro, México

$\mathrm{Tel}+$ I 442 I56 09I5

Email meneses@unam.mx 
human immunodeficiency virus infection, xerostomy), contributes to the proliferation of C. albicans, ${ }^{7,8}$ as well as to adherence of this pathogen in $60 \%$ of patients with removable prostheses. ${ }^{9,10}$ C. albicans has been shown to be an important opportunistic pathogen causing infection in the oral cavity and to be able to colonize acrylic materials. ${ }^{8,11}$ A cleaning routine may be instituted to prevent and remove accumulation of micro-organisms and to remove mucin, food remains, calculus, and stains. ${ }^{12}$

Silver nanoparticles can kill all pathogenic microorganisms, and no report as yet has shown that any organism can readily build up resistance to them. An easy, environmentally friendly approach was used to synthesize silver nanoparticles, given that biomolecules found in plants can reduce silver ions from silver nitrate to silver nanoparticles. ${ }^{13}$ An acrylic resin that can prevent adhesion of micro-organisms is currently unavailable. However, this study describes an acrylic resin containing silver nanoparticles that can be used to produce dentures with antifungal properties. Silver nanoparticles have been used for their antimicrobial effect in different biomedical applications, ${ }^{14}$ also in modifying commercial acrylic resins but not in the formulation of an experimental acrylic for denture bases. Silver nanoparticles are also reported to be nontoxic to humans and very effective against bacteria, viruses, and other eukaryotic micro-organisms at very low concentrations and without side effects. ${ }^{15}$ For example, different concentrations of silver nanoparticles added to Lucitone 550 denture resin demonstrated an antimicrobial effect. $^{16}$

Although the literature reports various studies related to silver nanocomposites with antimicrobial applications in the medical field, ${ }^{14}$ very few studies concerning addition of silver nanoparticles to denture base resins have been published. ${ }^{17}$ A pilot study demonstrated that silver nanoparticle-loaded chemically cured resins made with silver benzoate $0.2 \%$ and $0.5 \%(\mathrm{w} / \mathrm{w})$ which were tested in vitro for antibacterial activity against Streptococcus mutans. The results showed 52.4\% and $97.5 \%$ bacterial inhibition, respectively, and further work is now warranted to test for mechanical properties. ${ }^{18}$ Casemiro et al reported an evaluation of a commercial acrylic resin containing a $2.5 \%$ silver and zinc zeolite compound, the results of which indicated higher antimicrobial activity but decreased flexural and impact strength. ${ }^{17}$

Biological methods used for synthesis of silver nanoparticles are considered safe and ecologically sound for fabrication of nanomaterials as an alternative to conventional physical and chemical methods. ${ }^{19}$ Studies have indicated that biomolecules like proteins, phenols, and flavonoids not only play a role in reducing ions to the nanosize range, but also play an important role in the capping of nanoparticles. ${ }^{20}$ Reduction of silver ions using combinations of biomolecules found in these extracts, such as vitamins, enzymes/proteins, organic acids (such as citrates), amino acids, and polysaccharides, is an environmentally benign yet chemically complex process. $^{21}$

The aim of the present research was to develop an acrylic resin containing silver nanoparticles as an antifungal agent and test its biocompatibility to ensure production of a nontoxic antifungal compound for denture bases. The hypothesis tested was that silver nanoparticles added to PMMA acrylic resin would decrease adherence of $C$. albicans and result in a biocompatible material with flexural properties meeting those specified for denture bases.

\section{Materials and methods Synthesis of silver nanoparticles}

Natural synthesis was prepared using a plant infusion containing $12.15 \mathrm{~g}$ of Geranium maculatum leaves and $100 \mathrm{~mL}$ of deionized water, which acted as a reducing agent for the formation of silver nanoparticles from silver ions. In a round flask, $20 \mathrm{~mL}$ of ethylene glycol (Sigma-Aldrich, St Louis, MO) was heated at $176^{\circ} \mathrm{C}$, and $10 \mathrm{~mL}$ of the natural infusion was then added as drops. Five minutes later, $1.6 \mathrm{~mL}$ of $0.025 \mathrm{M}$ silver nitrate solution (Sigma-Aldrich) was added over 2 minutes. The resulting silver nanoparticles were washed twice in ethanol and acetone for 10 minutes, with sonication followed by centrifugation for 5 minutes at $7000 \mathrm{rpm} .^{22}$

\section{Spectroscopy analyses}

Ultraviolet-visible absorption spectroscopy was performed in a Spectronic Genesys 2PC Spectrophotometer (Triad Scientific; Manasquan, NJ) to confirm synthesis of silver nanoparticles. Raman dispersive spectroscopy was performed in a Senterra Dispersive Raman Microscope (Bruker, Billerica, MA) equipped with a $\lambda 685 \mathrm{~nm}$ laser and FT-Raman (Nicolet Analytical Instruments; Madison, WI) with $\lambda 1064 \mathrm{~nm}$ in the laser, coupled with an Olympus microscope. The silver nanoparticle solution was deposited on a sample holder without further preparation.

\section{Microscopy}

Transmission electron microscopy was performed using a JEOL-1010 electron microscope (JEOL, Peabody, MA). The samples were prepared by dropping silver nanoparticle solution onto the microscopy grids allowing evaporation of water. 


\section{PMMA-silver nanoparticle resin samples}

Pink PMMA powder was synthesized using the suspension polymerization technique, adding $\mathrm{TiO}_{2}$ and $\mathrm{Fe}_{2} \mathrm{O}_{3}$ nanoparticles in situ as pigments. ${ }^{23}$ Discs measuring $20 \mathrm{~mm} \times 2 \mathrm{~mm}$ were obtained by mixing PMMA and methyl methacrylate monomer (MMA, Sigma-Aldrich) in a volume ratio of 3:1. The MMA monomer was added with $1 \mu \mathrm{g} / \mathrm{mL}$ of silver nanoparticles and $1 \%$ of benzoyl peroxide as an initiator before mixing with the PMMA powder. When the PMMA-silver nanoparticle mixture reached the plastic phase, it was packed into metallic molds to be polymerized by microwave irradiation at $500 \mathrm{~W}$ for 3 minutes. ${ }^{24}$

PMMA and PMMA-silver nanoparticle discs were prepared. The commercial acrylic resin, Nature Cryl ${ }^{\mathrm{TM}}$ MC (GC America Inc, Alsip, IL), was thermopolymerized following the manufacturer's instructions and used as a control. The discs were washed and sterilized under ultraviolet irradiation for 5 minutes prior to use in the Candida albicans assay and biocompatibility tests. Experimental and control acrylic samples were made for each group ( $\mathrm{n}=9$, minimum), according to International Organization for Standardization (ISO)-10993-5..$^{25}$

\section{C. albicans adherence test}

A C. albicans strain (90026) obtained from the American Tissue Culture Collection (ATCC, Manassas, VA) was cultured overnight in yeast broth (Sigma-Aldrich). Sterilized resin specimens $(n=9)$ were placed into 24 -well sterile culture plates (Nunc, Thermo Fisher Scientific, Roskilde, Denmark), and a $500 \mu \mathrm{L}$ yeast suspension containing $1 \times 10^{6}$ colony-forming units was added. After 24 hours of incubation at $37^{\circ} \mathrm{C}$, nonadherent cells were removed from the specimens by washing for 10 minutes under sonication, followed by three washings with distilled water for one minute each under shaking. Adherent fungi were extracted by incubation with $1.0 \mathrm{~mL}$ of benzalkonium chloride for 15 minutes. Finally, a microbial cell viability assay based on luminescent ATP measurement (Bac Titer-Glo ${ }^{\mathrm{TM}}$, Promega, Fitchburg, WI) was performed to determine the number of viable cells adhered to the acrylic resins. Aliquots of extract ( $20 \mu \mathrm{L}$ each) were mixed briefly with $30 \mu \mathrm{L}$ of BacTiter-Glo reagent in $1.5 \mathrm{~mL}$ clear Eppendorf tubes, and luminescence was recorded after 5 minutes in a 20/20 luminometer (Turner Biosystems, Sunnyvale, CA) at a wavelength emission of $590 \mathrm{~nm}$. Relative luminescence intensity was measured in 10 -second integration periods. The experiment was carried out in triplicate. ${ }^{23}$

\section{Cell culture}

NIH-3T3 mouse fibroblasts were used as adherent cells to determine the toxicity of the nanomaterials. 3T3 cells are derived from different mouse strains, and this strain was obtained from the National Institutes of Health in the US. ${ }^{26}$ The NIH-3T3 fibroblasts (ATCC CRL-1658) were maintained in Dulbecco's Modified Eagle's Medium (Gibco, Invitrogen, Carlsbad, CA) containing 10\% fetal bovine serum (Gibco) and $100 \mathrm{U} / \mathrm{mL}$ penicillin-streptomycin at $37^{\circ} \mathrm{C}$ in $5 \% \mathrm{CO}_{2}$ with $95 \%$ humidity. The cells were plated into 24-well sterile plates (Nunc) at a concentration of $1 \times 10^{4}$ cells per well and incubated in $500 \mu \mathrm{L}$ of culture medium. After 24 hours, the culture medium was renewed, and the specimens were carefully deposited in direct contact with the NIH-3T3 cell monolayer.

Relevant cell types used to analyze the toxicity of nanomaterials include leukocytes in culture. ${ }^{27}$ Jurkat cells are human $\mathrm{T}$ lymphocytes established from the peripheral blood of patients with acute T cell leukemia. Jurkat cells (ATCC TIB-152) were maintained in RPMI 1640 medium (Gibco) with the same conditions for cell culture as those described earlier. The cells were plated into 12 -well sterile plates at a concentration of $5 \times 10^{4}$ cells per well and incubated using $1 \mathrm{~mL}$ of culture medium. The specimens were then carefully deposited in direct contact with Jurkat cells.

\section{Toxicity and genotoxicity assays}

MTT and BrdU assays were performed using NIH-3T3 cells. Specimens from PMMA-silver nanoparticles, PMMA, and Nature Cryl were sterilized by exposure of both faces to ultraviolet irradiation for 5 minutes. Adherent cells were next exposed to the specimens and proliferation was assessed by reductase enzyme activity, indicated by transformation of MTT into a colored reduced form. ${ }^{23,28}$ After incubation for 24 hours and 72 hours, the resins were removed, an MTT assay was performed following the manufacturer's instructions, and absorbance was measured in a microplate reader (Bio-Rad 680, Hercules, CA) at a wavelength of $655 \mathrm{~nm}$, where:

$$
\begin{aligned}
\% \text { viability }= & \text { Optical density of the samples } / \text { optical } \\
& \text { density of the control group } \times 100 .
\end{aligned}
$$

The control specimen was a culture without acrylic resins. Samples were analyzed in triplicate, and three independent experiments were performed. For the BrdU assay, NIH3T3 cells were counted, placed onto culture plates, and maintained for 24 hours to obtain adherence. Twenty-four hours after exposure to the specimens, the medium was 
removed and the BrdU assay was performed according to the manufacturer's instructions (Roche, Indianapolis, IN). Briefly, after incubation of the cells in the presence of the samples, the samples were removed and $10 \mu \mathrm{L}$ of labeling solution was added for a 2-hour incubation period. Next, the medium was aspirated and a FixDenat solution was added and maintained for 30 minutes of incubation at room temperature. The liquid was then removed and $100 \mu \mathrm{L}$ of working solution (anti-BrdU POD and antibody dilution solution 1:100) was added for 90 minutes at room temperature. The liquid was removed and $150 \mu \mathrm{L}$ of washing solution was added twice. Finally, the liquid was removed and $100 \mu \mathrm{L}$ of substrate solution was added for incubation over 15 minutes at room temperature. Absorbance was measured by a microplate reader (Bio-Rad 680) at a wavelength of $415 \mathrm{~nm}$.

The Jurkat cells were counted using the manner described earlier, and then exposed to the specimens for 24 hours. The Comet assay was performed as previously reported, ${ }^{29}$ with some modifications. The glass slides were briefly coated with regular agarose $0.5 \%$ in a Tris/borate/EDTA buffer (TBE $1 \times$, Sigma-Aldrich). After 24 hours of incubation, the resins were removed from the cell culture and suspended in agarose type VII low gelling temperature (Sigma) at a final concentration of $0.7 \%$ in phosphate-buffered saline, $\mathrm{pH}$ 7.4. After solidification, a cover of agarose NA (GE Healthcare Bio-Science, Uppsala, Sweden) was placed at a concentration of $0.5 \%$ in phosphate-buffered saline. Next, the glass slides were incubated in the dark for 3 hours at $4{ }^{\circ} \mathrm{C}$ into a lysis buffer $(2.5 \mathrm{M} \mathrm{NaCl}, 10 \mathrm{mM}$ Tris, $10 \%$ dimethyl sulfoxide, and 1\% Triton X-100, Sigma). Electrophoresis was then carried out for 20 minutes at $25 \mathrm{~V}$ and $4{ }^{\circ} \mathrm{C}$ in TBE buffer ( $\mathrm{pH} 7.4$ ), followed by neutralization with Tris (hydroxymethyl) aminomethane hydrochloride (Tris-HCl, Sigma) at $\mathrm{pH} 7.5$ for 10 minutes. Staining was done with ethidium bromide in the dark for 20 minutes. The cell nuclei were observed directly using an ultraviolet light microscope (Leica, Chicago, IL) and photographed. Each experiment was performed in triplicate.

\section{Mechanical properties}

A flexural strength test was performed in accordance with ISO specification $1567 .{ }^{30}$ Five specimens $(65 \times 10 \times 2.5 \mathrm{~mm})$ from each group were fabricated and subjected to the flexural strength test in a universal testing machine (Zwick/ Roell-Z005) using three-point loading. A constant crosshead speed of $5 \pm 1 \mathrm{~mm}$ per minute was used and the load was applied until fracture. Mean flexural strength (MPa) and flexural modulus (GPa) were calculated.

\section{Microstructure of PMMA-silver nanoparticle acrylic resin}

Scanning electron microscopy was performed for the polymerized PMMA-silver nanoparticles to evaluate distribution of the silver nanoparticles in the acrylic resin. The observations were made using a JEOL JSM-6060LV scanning microscope.

\section{Statistical analysis}

Values are expressed as the mean \pm standard error of the mean. Statistically significant differences between groups were determined by analysis of variance followed by the unpaired Student's $t$-test using GraphPad Prism software (GraphPad Prism 5.0, Software Inc, La Jolla, CA). Differences between means were considered to be statistically significant at $P<0.05$.

\section{Results and discussion}

Recent advances in nanotechnology have helped us to modify the size and shape of nanoparticles, provided different ways in which to use these nanoparticles in the diagnosis and treatment of various diseases, and facilitated their application in fields such as bioscience and medicine. ${ }^{31,32}$ The efficacy of silver nanoparticles against $C$. albicans has been confirmed in some commercial dental materials. ${ }^{33}$ Nevertheless, to the authors' knowledge, no study to date has attempted to modify synthesized acrylic resins containing silver nanoparticles for dentures, or confirm an antifungal effect against $C$. albicans and cytocompatibility.

\section{Synthesis of silver nanoparticles}

The nanoparticles were prepared using a natural green infusion as a reduction agent. The silver nanoparticle solution prepared was light yellow in appearance, indicating formation of silver nanospheres. The reduction process was extracellular and rapid, enabling easy biosynthesis of silver nanoparticles. During glycolysis, plants produce a large amount of hydrogen ions along with nicotinamide adenine dinucleotide, which acts as a strong reducing agent, and this seems to be responsible for formation of the silver nanoparticles. Water-soluble antioxidant agents like ascorbic acid also seem to be responsible for reduction of silver nanoparticles.

The resulting silver nanoparticles show good antimicrobial activity against a number of common pathogens. ${ }^{13}$ As microbicides, these silver nanoparticles are interesting candidates for research because of their effectiveness in small doses and their minimal toxicity. ${ }^{32}$ They also indicate that use 
of plants for nanoparticle synthesis can be advantageous over other biological processes by circumventing the elaborate procedures required for maintaining cell cultures, ${ }^{34}$ as demonstrated in the present work.

\section{Spectroscopy analyses}

The samples show an optical absorption band peaking at about $410 \mathrm{~nm}$ (Figure 1A). This indicates typical absorption of metallic silver nanoclusters due to surface plasmon resonance and collection of spherical silver nanoparticles. ${ }^{13}$ Raman spectroscopy confirms characteristic peaks of silver particles at 1310, 1405, and $1600 \mathrm{~cm}^{-1}$ (Figure 1B). There are no other published spectra of silver nanoparticles for comparison.

\section{Transmission electron microscopy}

Figure $1 \mathrm{C}$ is an electron transmission micrograph showing spherically shaped silver nanoparticles in a size range of $10-20 \mathrm{~nm}$. The nanoparticles were placed in deionized water as a dispersing medium, allowing the particles to separate for more detailed observation. Transmission electron microscopy showed formation of well dispersed silver nanoparticles in the nanometric range. This is an important point because the antimicrobial activities of colloidal silver particles are influenced by the particle dimensions, with smaller particles having a greater antimicrobial effect. ${ }^{35}$

\section{Microbial adhesion and cellular compatibility}

Denture wearers are susceptible to colonization by C. albicans. ${ }^{36}$ Stomatitis is an inflammatory process of the oral mucosa associated with the presence of $C$. albicans, which is usually the major etiological agent. ${ }^{37}$ Herein, we performed microbial tests to assess for attachment of C. albicans, the most common oral pathogen, ${ }^{38}$ onto standard PMMA and PMMA-silver nanoparticle discs. As shown in Table 1, the PMMA-silver nanoparticle discs showed less C. albicans adherence and, compared with PMMA and Nature Cryl (commercial resin) discs, there was a statistically significant difference in adherence. This demonstrates the antifungal effect of silver nanoparticles when added to the PMMA formulation, suggesting that this novel acrylic resin could be developed as a denture base.

Given that the antifungal effect may be related to a wide spectrum of cellular toxicity, the activity of mouse fibroblasts and human lymphocytes cultured in the presence of standard and nanoparticle-containing materials was explored. Given that most dental materials release small amounts of various
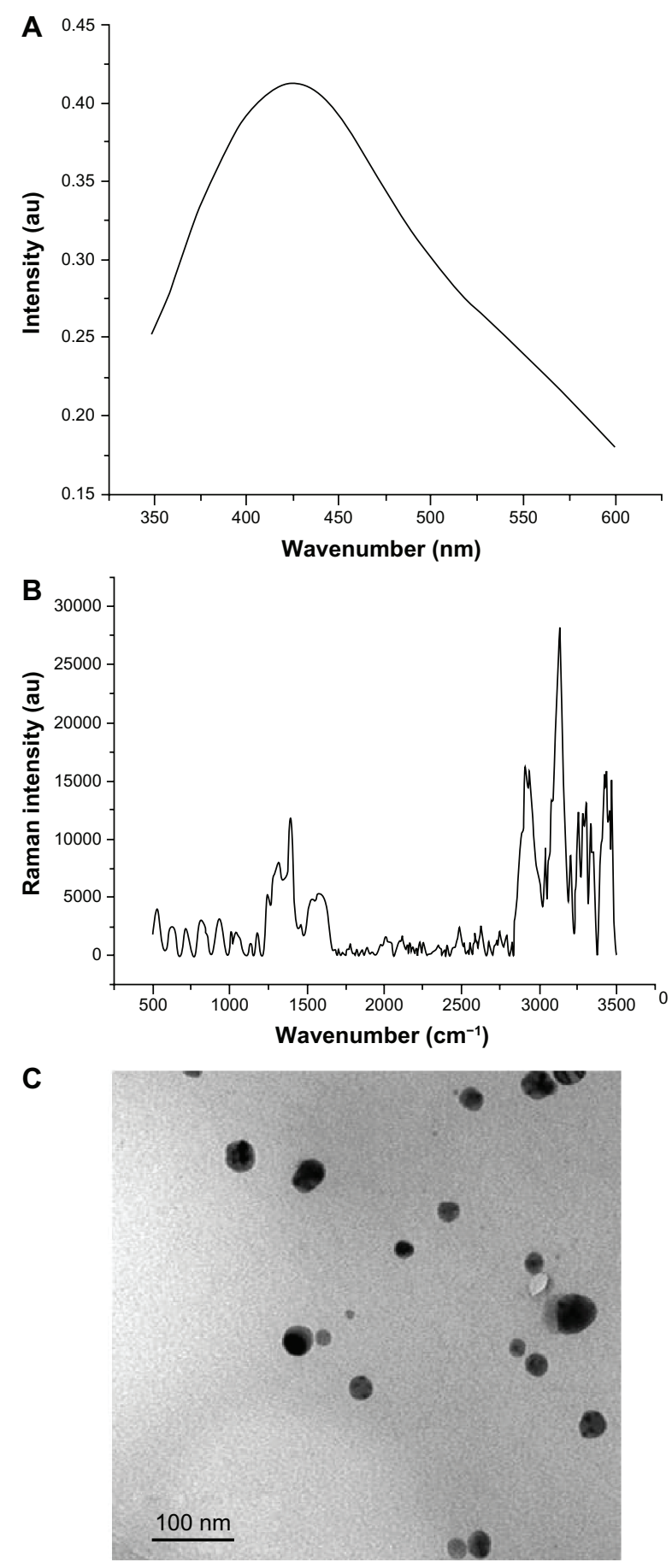

Figure I Silver nanoparticle analysis. (A) Ultraviolet spectrum showing the presence of plasmon at $410 \mathrm{~nm}$. (B) Raman dispersive spectra indicating characteristic peaks of silver nanoparticles at $1410 \mathrm{~cm}^{-1}$ and $1620 \mathrm{~cm}^{-1}$. (C) Transmission electron micrograph showing spherically shaped nanoparticles and particles measuring $10-20 \mathrm{~nm}$.

substances into their physiological environment (eg, the pulp and oral cavity), it is important to ensure that the potential cytotoxicity of dental materials is minimal, eg, ISO 10993-339 and ISO 10993-5, ${ }^{24}$ for cytotoxicity and genotoxicity in biomaterials, respectively. The hazardous and toxic effects 
Table I Adherence of Candida albicans was significantly reduced in the PMMA group with silver nanoparticles

\begin{tabular}{lc}
\hline Acrylic resins & Light relative units $\times 10^{3}$ \\
\hline PMMA/AgNPs & $4.8 \pm 0.5^{*}$ \\
PMMA & $11.5 \pm 1.2$ \\
Nature Cryl & $18.7 \pm 2.5$ \\
\hline
\end{tabular}

Note: $\mathrm{n}=9$, one-way analysis of variance, $* \mathrm{P}<0.05$

Abbreviation: PMMA, poly(methyl methacrylate).

of silver nanoparticles have not been studied extensively. ${ }^{40}$ The MTT assay, incorporation of BrdU test, and Comet assay are widely used to determine the potential toxicity of substances, ${ }^{41}$ so were used in the present study.

A metabolic enzyme assay, reflecting viability of cultured cells, demonstrated that the PMMA-silver nanoparticle discs showed biocompatible behavior in that they do not influence cell proliferation under conditions equivalent to those of untreated cells. According to the statistical analysis, it was determined that PMMA-silver nanoparticles versus PMMA $(P=0.7369)$ and PMMA-silver nanoparticles versus Nature Cryl $(P=0.8907)$ were not statistically different. Non-toxicity of PMMA and PMMA-silver nanoparticles was observed in the MTT assay including 24 hours and 72 hours of exposure (Figure 2A), and quantification is shown in Figure 2B. BrdU is a cellular immunoassay that uses a mouse monoclonal antibody directed against BrdU. The ability to detect a minimum number of proliferating cells in a given sample depends on the amount of BrdU incorporated into the cells and thus on the labeling period. The BrdU assay was used in mouse fibroblast cells in this study to assess for DNA

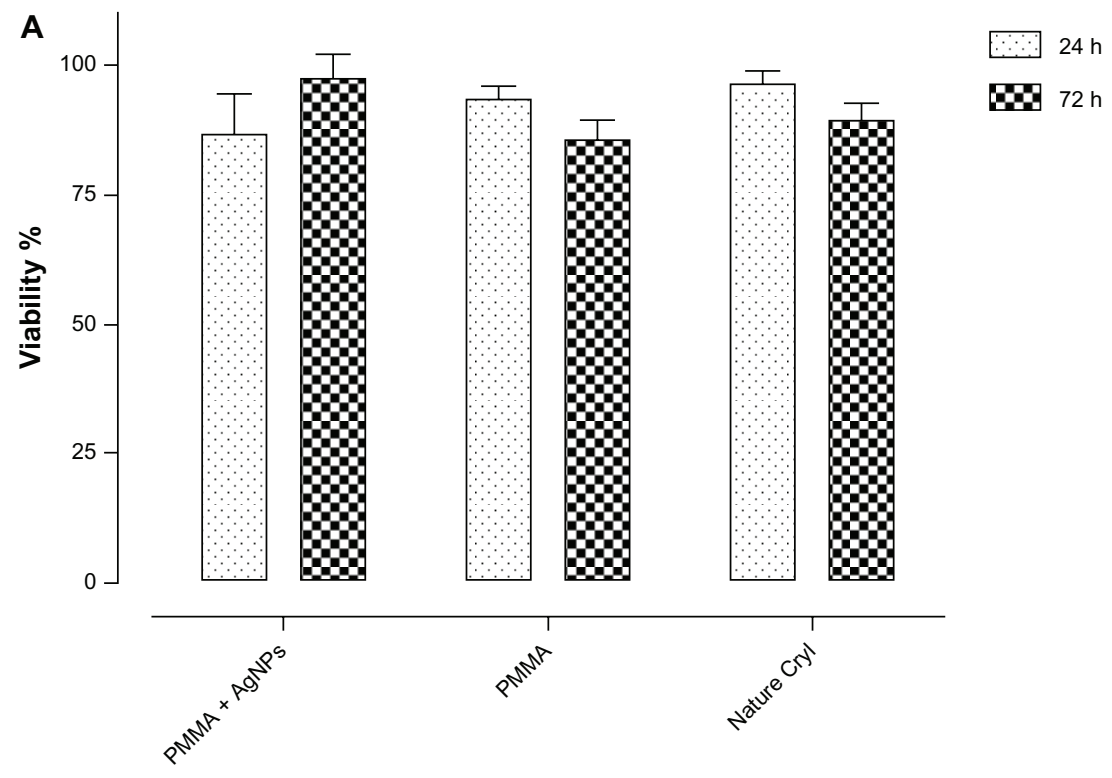

B

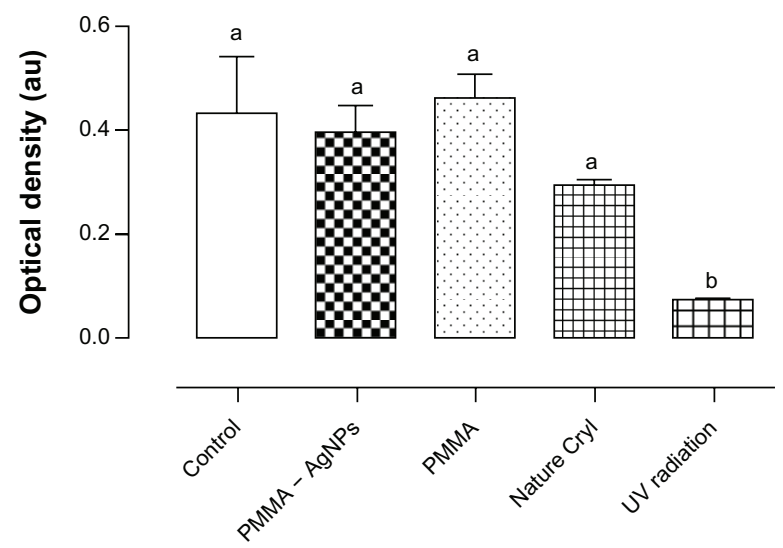

Figure 2 Biocompatibility in NIH-3T3 mouse cells. (A) MTT assay performed in PMMA and Nature Cryl ${ }^{\mathrm{TM}}$ groups showed no significant statistical differences at 24 hours and 72 hours. (B) Cells were exposed to PMMA formulations for 24 hours and proliferation was analyzed using BrdU antibodies.

Note: No significant differences were found between the groups according to one-way analysis of variance $(P \leq 0.05)$.

Abbreviation: PMMA, poly(methyl methacrylate). 
damage. The results show that proliferation of cells in all cases was not limited by the presence of the specimens. The experimental samples showed no significant differences, ie, PMMA-silver nanoparticles versus controls $(P=0.7603)$, PMMA versus controls $(P=0.8244)$, or Nature Cryl versus controls $(P=0.1887)$. However, cells exposed to ultraviolet radiation showed significant DNA damage $(P=0.0051)$.

Moreover, genotoxicity was assessed using human lymphocytes. The Comet assay, also called single-cell gel elec- trophoresis, is a sensitive and rapid technique for quantifying and analyzing DNA damage to individual cells. The image that is obtained resembles a "comet", with a distinct head and tail. The head is composed of intact DNA, while the tail consists of damaged (single-strand or double-strand breaks) or broken pieces of DNA. Applications of the Comet assay have included the study of mammalian cells. ${ }^{42}$ The results suggest no toxicity to cells, in contrast with cell exposed to ultraviolet radiation (Figure $3 \mathrm{~A}$ and $\mathrm{B}$ ). Where PMMA-

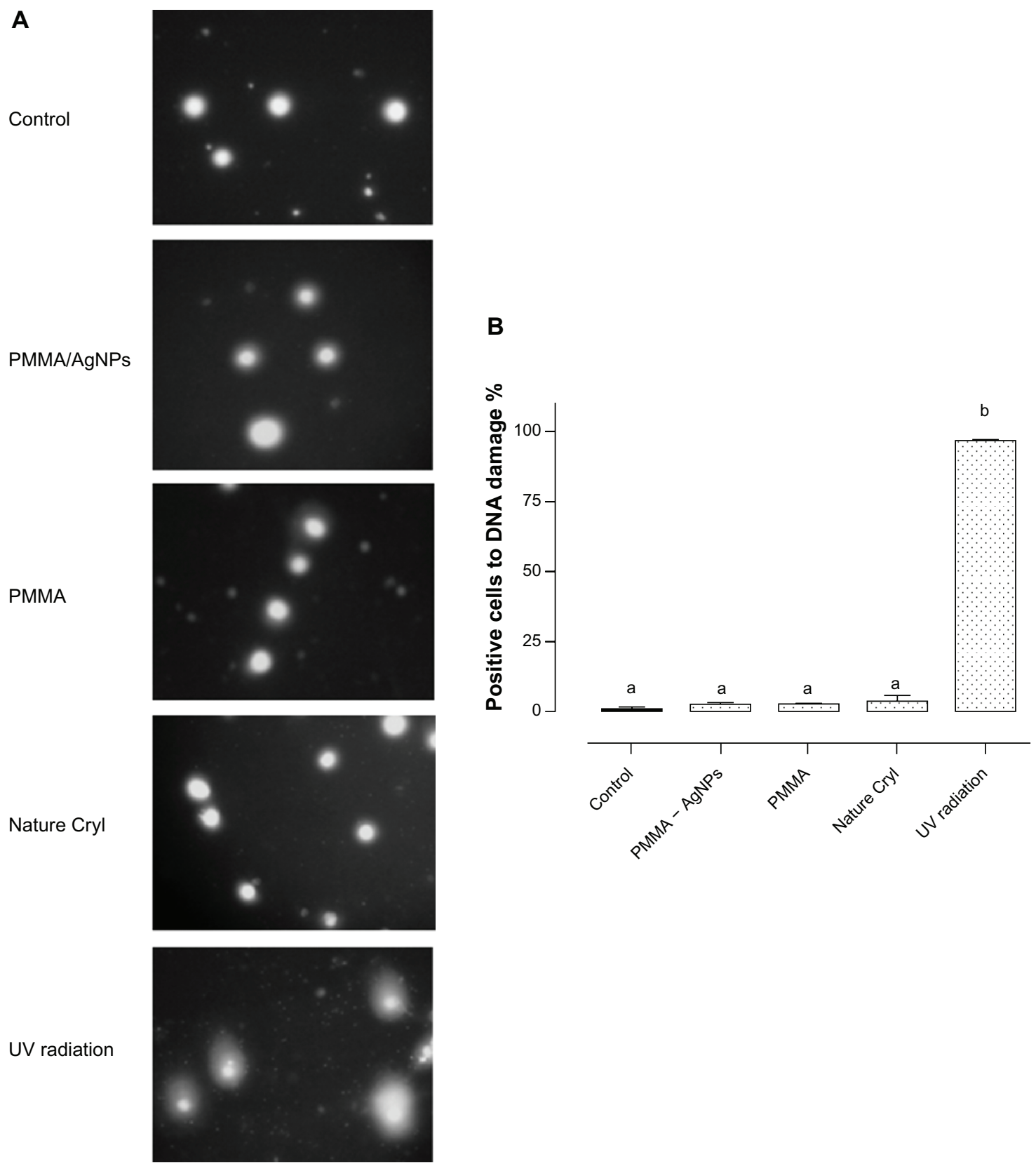

Figure 3 Genotoxic assay in Jurkat human cells. Comet assay images showing formation of tails when genotoxic cell damage was caused by contact with the acrylic materials. Images showing round cells indicate that the genetic DNA material is intact and that the cell nucleus has not been damaged. Jurkat cells exposed to direct ultraviolet irradiation for 5 minutes were used as a positive control. (A) Representative photographs of single-cell gel electrophoresis ethidium bromide-stained nuclei. (B) Corresponding quantitative analysis of positive cells with DNA damage $(P<0.05)$. 
silver nanoparticles versus controls $(P=0.5185)$, PMMA versus controls $(P=0.5185)$, Nature Cryl versus controls $(P=0.378)$, presented markedly significant differences when comparing to cells exposed to ultraviolet radiation versus controls $(P \leq 0.0001)$. Our results indicate that these materials could be used to make biocompatible resins.

Yen et $\mathrm{al}^{43}$ reported that smaller silver nanoparticles ( $3 \mathrm{~nm})$ are more cytotoxic than larger particles $(25 \mathrm{~nm})$, indicating the importance of particle size. In this context, the silver nanoparticles fabricated in the present study were larger, and it was confirmed that they did not cause cytotoxic or genotoxic damage in NIH-3T3 or in Jurkat cells. These results demonstrate that PMMA-silver nanoparticles are a suitable means of producing nontoxic materials with antimicrobial properties for use in dentistry.

\section{Mechanical properties}

The mean GPa and MPa of the three tested materials are shown in Table 2. Statistical analysis indicated significant differences in GPa between the PMMA, PMMA-silver nanoparticle, and Nature Cryl groups $(P<0.05)$. PMMA and PMMA-silver nanoparticles showed a higher MPa than Nature Cryl. On the other hand, the flexural strength of the Nature Cryl group was the highest (116.1 $\pm 10.73 \mathrm{MPa}$ ), followed by the PMMA and PMMAsilver nanoparticle groups. The PMMA-silver nanoparticle group showed a higher GPa and lower MPa compared with other materials analyzed here; however, both values were within the ISO-1567 specification (ie, at least $2000 \mathrm{GPa}$ and $65 \mathrm{MPa}$ ). ${ }^{30}$

\section{Microstructure of PMMA-silver nanoparticle acrylic resin}

Scanning electron microscopic analysis of the PMMA-silver nanoparticles (Figure 4) showed fairly good dispersion of silver nanoparticles in the polymer matrix, with little aggregation, which facilitated more release of silver ions and consequently higher antibacterial activity. ${ }^{44}$

Table 2 Main values and standard deviation of flexural modulus and flexural strength of the evaluated acrylic resin

\begin{tabular}{llc}
\hline Acrylic resin & $\begin{array}{l}\text { Flexural modulus* } \\
\text { (GPa) }\end{array}$ & $\begin{array}{l}\text { Flexural strength*** } \\
\text { (MPa) }\end{array}$ \\
\hline PMMA & $4.6 \pm 0.21^{\mathrm{a}}$ & $92.1 \pm 1.49^{\mathrm{a}}$ \\
PMMA + AgNPs & $3.9 \pm 0.25^{\mathrm{a}}$ & $76.2 \pm 0.25^{\mathrm{b}}$ \\
Nature Cryl & $3.3 \pm 0.32^{\mathrm{b}}$ & $116.1 \pm 10.73^{\mathrm{a}}$ \\
\hline
\end{tabular}

Notes: $*$ Different letters indicate significant difference, $P$ value $=0.0096$; $* *$ different letters indicate significant difference, $P$ value $=0.0078$.

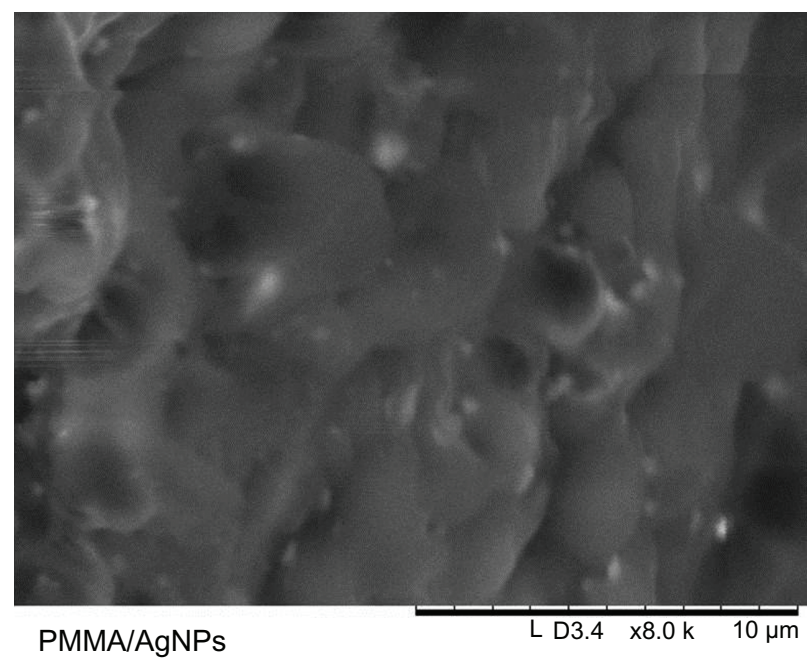

Figure 4 Scanning electron micrograph of PMMA-silver nanoparticles showing a homogeneous silver nanoparticle distribution in the PMMA matrix. Abbreviation: PMMA, poly(methyl methacrylate).

\section{Conclusion}

Spherical silver nanoparticles were synthesized and added to a PMMA formulation, resulting in successful reduction of adherence of C. albicans. The PMMA-silver nanoparticle compound developed was not found to be cytotoxic or genotoxic, according to mitochondrial enzymatic activity, estimation of DNA replication, and non-DNA genomic damage in culture cells. The flexural properties of the PMMA-silver nanoparticles acrylic resin were also evaluated showing that the main values were according to the ISO-1567. An antifungal biocompatible PMMA was developed as a denture base.

\section{Acknowledgments}

Drs Genoveva Hernández-Padrón, Marina Vega, Ofelia Mora, Rodrigo Hernández-Medina, María Lourdes Palma Tirado, Q Carmen Vázquez, Domingo Rangel, Miguel A Arellano, T Antonio Prado, and T Daniel Mondragón are thanked for their excellent technical assistance. Special thanks are also extended to the General Direction of Academic Personnel Matters at the National Autonomus University of Mexico (DGAPA-UNAM) Foundation.

\section{Disclosure}

The authors report no conflicts of interest in this work.

\section{References}

1. Shim JS, Watts DC. An examination of the stress distribution in a soft-lined acrylic resin mandibular complete denture by finite element analysis. Int J Prosthodont. 2000;13:19-24.

2. Waters MGJ, Williams DW, Jagger RG, Lewis MAO. Adherence of Candida albicans to experimental denture soft lining materials. $J$ Prosthet Dent. 1997;77:306-312. 
3. Coco BJ, Bagg J, Cross LJ, Jose A, Cross J, Ramage G. Mixed Candida albicans and Candida glabrata populations associated with the pathogenesis of denture stomatitis. Oral Microbiol Immunol. 2008;23:377-383.

4. Yildirim MS, Hasanreisoglu U, Hasirci N, Sultan N. Adherence of Candida albicans to glow-discharge modifies acrylic denture base polymers. J Oral Rehabil. 2005;32:518-525.

5. Diaz-Arnold AM, Vargas MA, Shaull KL. Flexural and fatigue strengths of denture base resin. J Prosthet Dent. 2008;100:47-51.

6. Bulad K, Taylor R, Verran J. Colonization and penetration of denture soft lining materials by Candida albicans. Dent Mater. 2004;20:167-175.

7. Boscato N, Radavelli A, Faccio D. Biofilm formation of Candida albicans on the surface of a soft denture-lining material. Gerodontology. 2009;26:210-213.

8. Oliveira HF, Silva-Lovato C, De Souza RF, Cruz PC, De Freitas-Pontes KM, Watanabe E. Effect of three methods for cleaning dentures on biofilms formed in vitro on acrylic resin.JProsthodont. 2009;18: 427-431.

9. Jorgensen E. Candida-associated denture stomatitis and angular cheilitis. In: Samaranayake LP, MacFarlane TW, editors. Oral Candidosis. London, UK: Butterworth; 1990.

10. Ramage G, Tomsett K, Wickers BL, López-Ribot J, Redding SW. Denture stomatitis: a role for Candida biofilms. Oral Surg Oral Med Oral Pathol Oral Radiol Endod. 2004;98:53-59.

11. Pusateri C, Monaco E, Edgerton M. Sensitivity of Candida albicans biofilm cells grown on denture acrylic to antifungal proteins and chlorhexidine. Arch Oral Biol. 2009;54:588-594.

12. Montagner H, Montagner F, Braun KO, Peres EC, Gomes BPF. In vitro antifungal action of different substances over microwaved-cured acrylic resins. J Appl Oral Sci. 2009;17:432-435.

13. Ahmad N, Sharma S, Shamsi VN, Fatma A, Mehta BR. Biosynthesis of silver nanoparticles from Desmodium triflorum: a novel approach towards weed utilization. Biotechnol Res Int. 2011. Article ID 454090.

14. Damm C, Münstedt H. Kinetic aspects of the silver ion release from antimicrobial polyamide/silver nanocomposites. Appl Phys A Mater Sci Process. 2008;91:479-486.

15. Jeong SH, Yeo SY, Yi CS. The effect of filler particle size on the antibacterial properties of compounded polymer/silver fibers. J Mater Sci. 2005;40:5407-5411.

16. Monteiro DR, Gorup LF, Takamiya AS, Rodrigues D, Ruvolo AC, Barbosa DB. Silver distribution and release from an antimicrobial denture base resin containing silver colloidal nanoparticles. J Prosthodont. 2012;21:7-15.

17. Casemiro LA, Gomes Martinis CH, Panzeri Pires-de-Souza FC, Panzeri H. Antimicrobial and mechanical properties of acrylic resins with incorporated silver-zinc zeolite - part I. Gerodontology. 2008;25: 187-194.

18. Monteiro DR, Gorup LF, Takamiya AS, Rodrigues D, Ruvolo AC, Barbosa DB. Silver distribution and release from an antimicrobial denture base resin containing silver colloidal nanoparticles. $J$ Prosthodont. 2012;2:7-15

19. Jha AK, Prasad K, Kulkarni AR. Synthesis of $\mathrm{TiO}_{2}$ nanoparticles using microorganisms. Colloids Surf B Interfaces. 2009;71:226-229.

20. Vedpriya A. Living systems: eco-friendly nanofactories. $J$ Nanomat Biostruct. 2010;5:9-21.

21. Ahmad N, Alam MK, Singh VN, Sharma S. Bioprospecting AgNPs from wild desmodium species. Journal of Bionanoscience. 2009;3: 97-104.

22. Shankar SS, Ahmad A, Sastry M. Geranium leaf assisted biosynthesis of silver nanoparticles. Biotechnol Prog. 2003;19:1627-1631.

23. Acosta-Torres LS, López-Marín LM, Nuñez-Anita RE, HernándezPadrón G, Castaño VM. Biocompatible metal-oxide nanoparticles: nanotechnology improvement of conventional prosthetic acrylic resins. J Nanomater. 2011. Article ID 941561.

24. Acosta-Torres LS, Barceló-Santana FH, Álvarez-Gayosso CA, ReyesGasga J. Synthesis and characterization of poly(methyl methacrylate) polymerized by microwave energy or conventional water bath. $J$ Appl Polym Sci. 2008;109:3953-3960.
25. International Organization for Standardization. 10993-5 Part 5. Test for in vitro cytotoxicity International Standard, biological evaluation of medical devices. Geneva, Switzerland: International Organization for Standardization;. Available from: http://www.iso.org/iso/home/store/ catalogue_ics/catalogue_detail_ics.htm?csnumber=26211. Accessed July 30, 2012

26. Travan A, Pelillo C, Donati I, et al. Non-cytotoxic silver nanoparticlepolysaccharide nanocomposites with antimicrobial activity. Biomacromolecules. 2009;10:1429-1435.

27. Jones C, Grainger DW. In vitro assessments of nanomaterial toxicity. Adv Drug Deliv Rev. 2009;61:438-456.

28. Mosmann T. Rapid colorimetric assay for cellular growth and survival: application to proliferation and cytotoxicity assays. J Immunol Methods. 1983;65(1-2):55-63.

29. Corona-Vadillo D, Cram-Heydrich S, Rojas del Castillo E. Ensayo de genotoxicidad con la lombriz de tierra Eisenia Andrei. In: Ensayos toxicológicos para la evaluación de sustancias químicas en agua y suelo. México DF, Mexico: Instituto Nacional de Ecología; 2008. [Assay of genotoxicity with the earthworm Eisenia Andrei. In: Toxicological assays for evaluation of chemicals in water and soil. Mexico City, Mexico: National Institute of Ecology, 2008]. Spanish.

30. International Organization for Standardization. 1567. Dentistry denture base polymers. Geneva, Switzerland: International Organization for Standardization; 1999

31. Salata OV. Applications of nanoparticles in biology and medicine. J Nanobiotechnology. 2004;2:3

32. Lara HH, Garza-Treviño EN, Turrent LI, Singh DK. Silver nanoparticles are broad-spectrum bactericidal and virucidal compounds. J Nanobiotechnology. 2011;9:30.

33. Chladek G, Mertas A, Barszczewska-Rybarek I, Nalewajek T, Zmudzki J, Krol W. Antifungal activity of dentures soft lining material modified by silver nanoparticles - a pilot study. Int J Mol Sci. 2011;12: 4735-4744.

34. Kaviya S, Santhanalakshmi J, Viswanathan B. Green synthesis of silver nanoparticles using Polyalthia longifolia leaf extract along with D-sorbitol: study of antibacterial activity. J Nanotechnology. 2011. Article ID 152970.

35. Balan L, Schneider R, Lougnot DJ. A new and convenient route to polyacrylate/silver nanocomposites by light-induced cross-linking polymerization. Prog Org Coat. 2008;62:351-357.

36. Dar-Odeh NS, Shehabi AA. Oral candidosis in patients with removable dentures. Mycoses. 2003;46:187-191.

37. Akpan A, Morgan R. Oral candidiasis. Postgrad Med J. 2002;78: 455-459.

38. Saboktakin MR, Tabatabaie RM, Maharramov A, Ramazanov MA. Synthesis and rheological properties of poly(methyl methacrylate)/ polymethacrylic acid nanocomposites as denture resins. Composite Part B Engin. 2011;42:851-855.

39. International Organization for Standardization. 10993-3. Part 3: Tests for genotoxicity, carcinogenicity and reproductive toxicity. International Standard, biological evaluation of medical devices. Geneva, Switzerland: International Organization for Standardization; 1999. Available from: http://www.iso.org/iso/catalogue_detail.htm?csnumber=32162. Accessed July 30, 2012.

40. Arora S, Jain J, Rajwade JM, Paknikar KM. Interactions of silver nanoparticles with primary mouse fibroblasts and liver cells. Toxicol Appl Pharmacol. 2009;236:310-318.

41. Meric G, Dahl JE, Ruyter IE. Cytotoxicity of silica-glass fiber reinforced composites. Dent Mater. 2008;24:1201-1206.

42. Peggy LO, Judit PB. The Comet assay: a method to measure DNA damage in individual cells. Nat Protoc. 2006;1:23-29.

43. Yen HJ, Hsu SH, Tsai CL. Cytotoxicity and immunological response of gold and silver nanoparticles of different sizes. Small. 2009;5: $1553-1561$.

44. Kassaee MZ, Akhavan A, Sheikh N, Sodagar A. Antibacterial effects of a new dental acrylic resin containing silver nanoparticles. J Appl Polym Sci. 2008;110:1699-1703. 


\section{Publish your work in this journal}

The International Journal of Nanomedicine is an international, peerreviewed journal focusing on the application of nanotechnology in diagnostics, therapeutics, and drug delivery systems throughout the biomedical field. This journal is indexed on PubMed Central, MedLine, CAS, SciSearch $\AA$, Current Contents ${ }^{\circledR} /$ Clinical Medicine,

Journal Citation Reports/Science Edition, EMBase, Scopus and the Elsevier Bibliographic databases. The manuscript management system is completely online and includes a very quick and fair peer-review system, which is all easy to use. Visit http://www.dovepress.com/ testimonials.php to read real quotes from published authors.

Submit your manuscript here: http://www.dovepress.com/international-journal-of-nanomedicine-journal 